\title{
Functional Performance, Pain and Strength in Patients with Knee Osteoarthritis after Photobiomodulation on Femoral Quadriceps Muscles. Study Protocol
}

\author{
André Cabral Sardim ${ }^{1 *}$,Johny Nelson de Almeida², Laura de Marchi $^{2}$,Carlos Eduardo Pinfildi ${ }^{3}$
}

${ }^{1}$ PhD student at Federal University of São Paulo - campus Baixada Santista. Department of Human Movement Science - Rua Silva Jardim, 136. Vila Mathias, Santos-SP. 11015-020. Brazil.

${ }^{2}$ Master degree student at Federal University of São Paulo - Department of Human Movement Science - campus Baixada Santista. Rua Silva Jardim, 136. Vila Mathias, Santos-SP. 11015-020. Brazil.

${ }^{3}$ Professor of Federal University of São Paulo - Physical Therapy - Department of Human Movement Science campus Baixada Santista. Rua Silva Jardim, 136. Vila Mathias, Santos-SP. 11015-020. Brazil.

Received: June 14, 2017; Accepted: June 22, 2017; Published: February 28, 2018

*Corresponding author: André Cabral Sardim, Federal University of São Paulo - Campus Baixada Santista - Santos - Brazil. Rua Silva Jardim 136. Vila Mathias ZipCode: 11015-020. E-mail: asardim@hotmail.com

\begin{abstract}
Background: Osteoarthritis $(\mathrm{OA})$ is the most prevalent rheumatic diseases in the elderly and is associated with pain, stiffness, deformity and progressive loss of function. Physical therapy through kinesiotherapy, proprioceptive exercises and physical agents can improve symptoms related
\end{abstract} to $\mathrm{OA}$.

Objective: The objective of the present clinical trial was to assess the functional performance, pain and muscular strength in patients with knee OA after phototherapy in the quadriceps femoral muscle.

Design: The study was a two-armed controlled randomized clinical trial.

Setting: The setting for this trial will be a physiotherapy clinic.

Participants: The study participants will be those who seek physiotherapy care unit spontaneously after receiving a diagnosis of knee osteoarthritis by a medical specialist.

Intervention: Participants performed a rehabilitation protocol that consisted of sensorimotor training and muscle strengthening and stretching exercises, for $60 \mathrm{~min}$, three times a week for 12 weeks. In addition to intervention with exercises, the Phototherapy group will receive phototherapeutic applications on the quadriceps femoral muscle while the placebo group will receive sham phototherapy application.

Measurements: All patients will be assessed pre-and post-treatment with SF-36 (Short Form 36), WOMAC (Western Ontario and McMaster Universities Osteoarthritis Index), the Berg balance scale, VAS (Visual Analogue Scale), ROM (range of motion) and muscle strength assessment.

Conclusion: If phototherapy is beneficial, the results of the study will help in the discussion of treatment guidelines for patients with knee $\mathrm{OA}$ focused on functional performance and analgesia combined to exercises and phototherapy. It may also help therapists to make clinical decisions based on high-quality studies.

Keywords: Phototherapy; Osteoarthritis; Exercise; Physiotherapy; Photobiostimulation

\section{Introduction}

Osteoarthritis $(\mathrm{OA})$ is a disease with high impact on public health because it directly affects the quality-of-life and the patient's activities of daily living. It is also one of the main reasons for invalid retirement and generates high costs $[1,2]$.

The American College of Rheumatology defines OA as a heterogeneous group of conditions that starts in the joints, associated with symptoms and effects in the integrity of the particular cartilage being related to changes in the cortical bone and in the joint edge [3].
This disease is characterized by pain, joint stiffness, deformity and progressive loss functional [4]. It can be considered that this affliction affects the individual in multiple dimensions including the organic and social levels [5]. As the characteristic of the disease is slow and progressive, it primarily affects individuals equally in both sexes from middle age onwards, although in women the incidence is higher after the menopause period, due to reduced hormone levels. The most commonly joints affected with $\mathrm{OA}$ are hands, feet, knees, hips, cervical and lumbar spine [4]. 
The main objective of knee OA treatment should not be directed only to relieving the symptoms but also to improving the functional capacity, because no specific modality has been established that leads to the cure of OA. When choosing the therapy, the standard treatment includes physiotherapy, weight loss, physical conditioning programs and use of orthosis, associated to the use of analgesic and anti-inflammatory drugs in cases where good responses was not obtained in pain control and functional improvement [4-7]. When the conservative treatment is not effective, surgery was considered to place a knee prosthesis [8].

Therapeutic exercises are part of the main treatment method associated to orientations and supervisions [9]. There is evidence that shows the importance of exercises for pain reduction and functional improvement in patients with OA [10]. Aerobic exercises are also very important to rehabilitate patients with $\mathrm{OA}$, increasing the lung capacity and consequently decreasing the fatigue and pain, and in improving the gait functionality [11]. Physical exercises focused in sensorimotor training are important because of the proprioceptive changes in knees with OA $[12,13]$.

Physical agents play an important role in knee $\mathrm{OA}$ treatment. Currently phototherapy or light therapy is one of the most studied modalities that shows good results for improvement when associated to an exercise protocol $[14,15]$.

It is known that phototherapy produces physiological effects mediated by photochemical actions at cellular level. It has also being shown to regulate chondroitin, proteoglycans and collagen proliferation [16]. Some of the mechanisms suggested are increased mitochondrial activity, increased cell oxygenation and increased ATP production [17].

Some studies have shown that phototherapy can also be used to improve the muscular performance of healthy individuals [18-22]. A study by Toma and collaborators (2013) stimulated the quadriceps femoral muscle of healthy elderly patients with phototherapy, carried out muscle strengthening training and observed increase in the number of exercise repetitions for knee extending and flexion [23].

Associated to a physical training program, phototherapy may be an important treatment alternative, helping to decrease stiffness and pain, increasing the amplitude of knee movement, and generating an increase in muscular strength $[14,20,21]$. Although studies indicate that phototherapy influences the improvement in muscular performance in healthy individuals, to date studies have not been found in the literature with phototherapy application to the quadriceps femoral muscle, associated to sensorimotor training, muscle strengthening and stretching exercises in patients with knee OA. Therefore, the objective of the present clinical trial was to assess the functional performance, pain and muscular strength in patients with knee OA after phototherapy on the quadriceps femoral muscle. This study is designed as a two-armed controlled randomized clinical trial.

\section{Methods \\ Participants}

Patients who search spontaneously the physiotherapy service of the clinic or who were forwarded by other medical services, clinically diagnosed with unilateral or bilateral knee OA according to the criteria of the American College of Rheumatology and presenting $\mathrm{x}$-ray with Kellgren-Lawrance classification grades II or III[24].

\section{Inclusion criteria}

1. Age over 55 years old.

2. Osteoarthritis in the knee joint (unilateral or bilateral) for at least two years.

3. Pain in three of the following situations: go up or down stairs, kneeling, sitting down and getting up, running, and standing unsupported for 2 minutes.

4. Kellgren-Lawrence classification grades II or III.

5. Body mass index less than $35 \mathrm{~kg} / \mathrm{h}^{2}$.

\section{Exclusion criteria}

1. Uncontrolled diabetes mellitus.

2. Untreated high blood pressure.

3. Fibromyalgia.

4. Neurological deficits (motor or sensory).

5. Peripheral neuropathies.

6. Fractures in the lower members.

7. Frequent physical activity practitioners (more than twice a week).

8. Alcoholics.

9. Smokers.

10. Individuals with cancer diagnosis.

11. Do not accept to take part in the study.

\section{Intervention}

The patients will be placed into groups of 20 individuals by a computerized randomization table with secret allocation in sealed and opaque cover.

In group 1 (rehabilitation protocol with sham phototherapy) the patients will be submitted to the treatment protocol proposed for the study and the placebo will be applied with the device turned off.

In group 2 (rehabilitation protocol with phototherapy) the patients will be submitted to the same treatment protocol and to phototherapy with cluster equipment (Cluster Physio Laser, DMC group, Sao Carlos - SP - Brazil), containing 7 visible diodes $(630 \mathrm{~nm})$ and 7 infrared diodes $(850 \mathrm{~nm}), 100 \mathrm{~mW}$ potency each diode, 4J energy each, 56J energy per area, totaling 168J per 
lower member. The radiation time will be 40 seconds per site, with a total of 120 seconds per member, in continuous mode. The phototherapy application will be stationary, in contact and perpendicular to the skin.

The application sites will be three areas of the quadriceps femoris muscle belly, bilaterally. A mark will be made with a hydrographic pen $2 \mathrm{~cm}$ above the upper pole of the knee patella. From this mark, the phototherapy will be applied in the middle region (vastus medialis muscle), side region (vastus laterals muscle) and central region (vastus intermedius and rectus femoris). These sites were established to irradiate the greatest part of the vastus muscles belly.

The treatment protocol will lasts 12 weeks with a frequency of three days per week. The protocol will be carried out in three steps: warm-up, muscular strengthening training and cool-down. Each session will last approximately $60 \mathrm{~min}$.

The progression of the balance exercises will be individualized, and will be performed with exercises without support on the bars, with steps of different heights, also with training in a stationary position, on unstable ground, with eyes open or closed, in tandem position and standing on one foot. In addition, the progression for the hamstrings and quadriceps femoral strengthening exercises will follow the maximum repetition protocol [25].

\section{Maximum Repetition Test}

The workload for the hamstrings and quadriceps femoris muscle exercises will be determined by the method of 4 to 8 repetitions to avoid excessive overload25. In this way the subjects will be asked to perform each exercise with a weight estimated by the researchers to allow a maximum of 4 to 8 repetitions. Based on the estimated load table, proposed by Baechle and Earle, 75\% intensity will be obtained of one Maximum repetition (1-MR) that will be considered the workload for the exercise protocol and this will be adjusted every two weeks by the same method [26]. The interval (rest) between the series will be of $1 \mathrm{~min}$.

Before starting any of the strength training procedures, the individuals will have a two-week adaptation period that will consist of two series of 15 repetitions with low loads, in this period correct execution of the exercises and familiarization with strength training will be emphasized. The individuals will carry out high intensity strength training for a period of 10 weeks completing therefore 12 weeks of the total training period.

\section{Assessments}

All the patients will be assessed pre-and post treatment by the same researcher who will not know to which group the patients belong.

\section{Primary assessment}

VAS (Visual Analogue Scale): a scale from 0 to 10 , where 0 is no pain and 10 the worst pain reported by the individual, and only the assessor has access to the numerical part [27].

\section{Secondary assessments}

WOMAC: self reporting questionnaire that assesses pain, joint stiffness and physical function, divided into 24 questions. The answers vary with scoring from 1 to 5 [28].

Range Of Motion (Goniometry): The patient will remain in decubitus dorsal, where the joint amplitude of passive and active knee extension and flexion will be assessed. For the extension a role will be placed under the heel of the patient, thus permitting an assessment of the knee stretch/extension. For knee flexion, the patient will remain with the hip bent at $90^{\circ}$ so that the amplitude can be assessed. All the assessments will be carried out bilaterally [29].

BERG: Questionnaire that assesses functional balance performance based on 14 items common in daily activities. The maximum score that can be obtained is 56 , with a scale ranging from 0 to 4 in each question [30].

SF-36: A questionnaire with 36 questions that assesses the quality-of-life in eight different domains: functional capacity, limitation because of physical aspects, pain, general state of health, vitality, social aspects, emotional aspects and mental health [31].

Muscle Strength: The strength of the extending knee muscle will be assessed using a hand-held manual Dynamometer. Initially the volunteer will be trained to twitch quadriceps femoris group and later the device will be placed on the region above the ankle. In this way isometric contraction takes place of the required muscle, against gravity, for three seconds. Each test will be carried out three times, with a rest time of 30 seconds between tests. During all the tests, the assessor will repeat constantly the words "strength" and "go" as verbal incentive and the greatest force of the three repetitions in kilogram force (Kgf) will be considered as the final value [32].

\section{Statistical Analysis}

To study the performance of groups 1 to 2 in the time assessed, according to the variables of interest, the ANOVA model of analysis of variance will be used with repeated measurements and the multiple comparison method by Bonferroni. The SPSS 21.0 software will be used for statistical analysis.

\section{Sample Size Calculation}

The variable considered for the sample sizing will be the pain intensity. The variability data will be considered as initial information. The minimum significant difference from the clinical point of view between the pre- and post- assessments of the groups was three points. This difference was detected using a 0.05 level of significance with a minimum power of 0.80 . Thus the conclusion was a sample of 20 individuals per group.

\section{Blinding}

The therapist responsible for applying the laser will note to which group the individuals belong but will not carry out the assessments and/or the treatment. A dark sheet will be used to cover the application area so that the patient will not know 
whether he receives the active or placebo treatment. Furthermore, the researcher responsible for the assessments will not know to which group belong.

\section{Ethics}

A blind assessor will be responsible for assessing the inclusion and non-inclusion criteria. If included in the research, the individuals will be informed of the objectives of the study, randomized in one of the two groups and then will sign an informed consent forms. The assessment and treatment will be carried out in the University physiotherapy clinic. The present study was approved by the ethics in research committee of the university under number 244.406 and Registered in the Brazilian registration of Clinical trials $(\mathrm{ReBec})$ under number RBR-7gkwdj.

\section{Discussion}

Using this study protocol, we expect to be able to determine rehabilitation guidelines for patients with knee osteoarthritis for functional performance, analgesia and increase in muscular strength. We included the main aspects described in the literature that can improve the clinical situation of these patients, such as sensorimotor training and muscular strengthening and stretching exercises.

The differential of the present study is in the site of the phototherapy application, used on the quadriceps femoris muscle associated to a rehabilitation protocol with focus on functional aspects. The progression of the muscle strengthening exercises during the treatment will be detailed and individualized, respecting the evolution of the weight load and adaptation of each patient.

When compared with recent systematic revisions, our study will be in agreement with that proposed by Uthman et al. and Davis and MacKay who stimulated high intensity aerobic and anaerobic exercise following strictly the strengthing exercises, and an adequate time for rehabilitation, respecting the individual progression of each patient $[33,34]$.

To better understand the effects of phototherapy applied on the quadriceps femoral muscle, we used a placebo group with the same protocol carried out for both groups, thus making the phototherapy the only different resource during treatment.

The data obtained may help in the discussion of treatment guidelines for patients with knee $\mathrm{OA}$ focused on functional performance and analgesia combined to exercises and phototherapy. It may also help therapists to make clinical decisions based on high-quality studies.

\section{Acknowledgments}

We would like to thanks the SERFIS (Seção de Recuperação e Fisioterapia de Santos) for support during the research.

\section{Conflict of Interest}

All authors have no conflict of interest

\section{References}

1. Schaible HG. Mechanisms of Chronic Pain in Osteoarthritis. Curr Rheumatol Rep. 2012;14(6):549-556. doi:10.1007/s11926-0120279-x.

2. Xie F, Kovuc B, Jin X, He X, Wang M and Silvestre C. Economic and humanistic burden of osteoarthritis: a systematic review of large sample studies. Pharmacoecnomics. 2016;34(11):1087-1100. doi: 10.1007/s40273-016-0424-x.

3. Veronese N, Maggi S, Trevisan C, Noale M, De Rui M, Bolzetta F, Zambon $\mathrm{S}$, et al. Pain increases the risk of developing frailty in older adults with osteoarthritis. Pain Med. 2016;18(3):414-427. doi:10.1093/pm/ pnw163.

4. Bastick AN, Runhaar J, Belo JN, Bierma-Zeinstra SM. Prognostic factors for progression of clinical osteoarthritis of the knee: a systematic review of observational studies. Arthritis Res Ther. 2015;17:152. doi:10.1186/s13075-015-0670-x.

5. Broderick JE, Junghaenel DU, Schneider S, Bruckenthal P, Keefe FJ. Treatment expectation for pain coping skills training: relationship to osteoarthritis patient's baseline psychosocial characteristics. Clin J Pain. 2011;27(4):315-322. doi:10.1097/AJP.0b013e3182048549.

6. Bennel KL, Wrigley TV, Hunt MA, Lim BW, Hinman RS. Update on the role of muscle in the genesis and management of knee osteoarthritis. Rheum Dis Clin North Am. 2013;39(1):145-76. doi: 10.1016/j. rdc.2012.11.003

7. McAlindon TE, Bannuru RR, Sullivan MC, Arden NK, Berenbaum F, Bierna-Zeinstra SM, et al. OARSI guidelines for the non-surgical management of knee osteoarthritis. Osteoarthritis Cartilage. 2014;22(3):363-388. doi:10.1016/j.joca.2014.01.003.

8. Zhang W, Moskowitz RW, Nuki G, Abramson S, Altman RD, Arden $\mathrm{N}$, et al. OARSI recommendations for the management of hip and knee osteoarthritis, Part II: OARSI evidence-based, expert consensus guidelines. Osteoarthritis Cartilage. 2008;16(2):137-162. doi:10.1016/j.joca.2007.12.013.

9. Juhl C, Christensen R, Roos EM, Zhang W, Lund H. Impact of exercise type and dose on pain and disability in knee osteoarthritis: a systematic review and meta-regression analysis of randomized controlled trials. Arthritis Rheumatol. 2014;66(3):622-636. doi:10.1002/art.38290.

10. Fransen M, McConnellS. Exercise for osteoarthritis of theknee.Cochrane Database Syst Rev. 2015;1:CD004376. doi:10.1002/14651858. CD004376.pub3.

11. Brosseau L, MacLeay L, Welch V, Tugwell P, Wells G. Intensity of exercise for the treatment of osteoarthritis. Cochrane Database Syst Rev. 2013;2:CD004259. doi:10.1002/14651858.CD004259.pub2.

12. Chang AH, Lee SJ, Zhao H, Ren Y, Zhang LQ. Impaired varus-valgus proprioception and neuromuscular stabilization in medial knee osteoarthritits. J Biomech. 2014;47(2):360-366. doi:10.1016/j. jbiomech.2013.11.024.

13. Baert IA, Mahmoudian A, Nieuwenhuys A, Jonkers I, Staes F, Luyten FP, et al. Proprioceptive accuracy in women with early and estabilished knee osteoarthritis and its relation to functional ability, postural control, and muscle strength. Clin Rheumatol. 2013;32(9):1365-1374. doi:10.1007/s10067-013-2285-4. 
14. Brosseau L, Robinson V, Wells G, Debie R, Gam A, Harman K, et al. Low level laser therapy (Classes I, II and III) for treating osteoarthritis. Cochrane Database Syst Rev. 2004;3:CD002046. doi:10.1002/14651858.CD002046.pub3.

15. Alfredo PP, Bjordal JM, Drever SH, Meneses SR, Zaquetti G, Ovanessian $\mathrm{V}$, et al. Efficacy of low level laser therapy associated with exercises in knee osteoarthritis: a randomized double-blind study. Clin Rehabil. 2012;26(6):523-33. doi10.1177/0269215511425962.

16. de Souza M, de Medeiros VP, Toma L, Reginato RD, Katchburian E, Nader HB, et al. The low level laser therapy effect on the remodeling of bone extracellular matrix. Photochem Phtobiol. 2012;88(5):12931301. doi: 10.1111/j.1751-1097.2012.01172.x.

17. Ferraresi C, Parizotto NA, Pires de Sousa MV, Kaippert B, Huang YY, Koiso $\mathrm{T}$, et al. Light-emitting diode therapy in exercise-trained mice increases muscle performance, cytochrome c oxidase activity, ATP and cell proliferation. J Biophotonics. 2015;8(9):740-754. doi:10.1002/ jbio.201400087.

18. Leal Junior ECP, Lopes-Martins RAB, Rossi RP, De Marchi T, Baroni BM, Godoi $\mathrm{V}$, et al. Effect of cluster multi-diode light emitting diode therapy (LEDT) on exercise-induced skeletal muscle ftigue and skeletal muscle recovery in humans. Lasers Surg Med. 2009;41(1):572-577. doi:10.1002/lsm.20810.

19. Baroni BM, Leal Junior ECP, Geremia JM, Diefenthaeler F, Vaz MA. Effect of light-emitting diodes therapy (LEDT) on knee extensor muscle fatigue. Photomed Laser Surg. 2010;28(5):653-658. doi:10.1089/ pho.2009.2688.

20. Vieira WHB, Ferraresi C, Perez SEA, Baldissera V, Parizotto NA. Effects of low-level laser therapy ( $808 \mathrm{~nm}$ ) on isokinetic muscle performance of young women submitted to endurance training: a randomized controlled clinical trial. Lasers Med Sci. 2012;27(1):497-504. doi:10.1007/s10103-011-0984-0.

21. Leal Junior ECP, Lopes-Martins, RAB, Frigo L, Marchi T, Rossi RP, et al. Effects of low-level laser therapy (LLLT) in the development of exercise-induced skeletal muscle fatigue and changes in biochemical markers related to post exercise recovery. J Orthop Sports Phys Ther. 2010;40(8):524-532. doi:10.2519/jospt.2010.3294.

22. Baroni BM, Leal Junior ECP, Marchi T, Lopes AL, Salvador M and Vaz MA. Low level laser therapy before eccentric exercise reduces muscle damage markers in humans. Eur J Appl Physiol. 2010;110(4):789-796. doi: 10.1007/s00421-010-1562-z.
23. Toma RL, Tucci HT, Antunes HKM, Pedroni CR, Oliveira AS, Buck I, et al. Effect of $808 \mathrm{~nm}$ low-level laser therapy in exercise-induced skeletal muscle fatigue in elderly women. Lasers Med Sci. 2013;28(5):13751382. doi:10.1007/s1010301212465.

24. Kellgren JH, Lawrence JS. Radiological Assessment of osteo-arthroses. Ann Rheum Dis. 1957;16:494. PMID: 13498604

25. Caserotti P, Aagaard P, Larsen JB, Puggaard L. Explosive heavyresistance training in old and very old adults: changes in rapid muscle force, strength and power. Scand J Med Sci Sports. 2008;18(6):773782. doi:10.1111/j.1600-0838.2007.00732.x.

26. Baechle TR, Earle RW. Essentials of Strength Training and Conditioning. 2nd Edition, Illinois, USA: Human Kinetics Publishers, NSCA; 2000.

27. Peter WF, Jansen MJ, Hurkmans EJ, Bloo H, Dekker J, Diling RG, et al. Physiotherapy in hip and knee osteoarthritis: development of a practice guidelines concerning initial assessment, treatment and evaluation. Acta Reumatol Port. 2011;36(3):268-81.

28. Fernandes MI, Ferraz MB, Ciconelli RM. Tradução e validação do Questionário de Qualidade de Vida Específico para Osteoartrose (WOMAC) para a língua portuguesa. Rev Paulista Reumatol. 2003;10:25.

29. Marques AP. Manual de goniometria. São Paulo: Editora Manole. 2003. 30. Miyamoto ST, Junior IL, Berg KO, Ramos LR, Natour J. Brazilian version of the Berg balance scale. Braz J Med Biol Res 2004;37(9):1411-1421. doi:org/10.1590/S0100-879X2004000900017.

31. Ciconelli RM, Ferraz MB, Santos W, Meinão I, Quaresma MR. Tradução para a língua portuguesa e validação do questionário genérico de avaliação de qualidade de vida SF-36 (Brasil SF-36). Rev Bras Reumatol. 1999;39(3):143-150.

32. Martin HJ, Yule V, Sydall HE, Dennison EM, Cooper C and Sayer AA. Is hand-held dynamometry useful for the measurement of quadriceps strength in older people? A comparison with the gold standard Biodex dynamometry. Gerontology. 2005;52(3):154-159. doi:10.1159/000091824.

33. Uthman OA, van der Windt DA, Jordan JL, Dziedzic KS, Healey EL, Peat GM, et al. Exercise for lower limb osteoarthritis: systematic review incorporating trial sequential analysis and network meta-analysis. BMJ. 2013;347:f5555. doi:10.1136/bmj.f5555.

34. Davis AM, Mackay C. Osteoarthritis year in review: outcome of rehabilitation. Osteoarthritis Cartilage. 2013;21(10):1414-1424. doi:10.1016/j.joca.2013.08.013. 